\title{
Avaliação do Desenvolvimento Motor de Crianças Institucionalizadas na Primeira Infância
}

\author{
Assessment of Motor Development in Institutionaliuzed Children in their Early Childhood \\ Fláviane Rezende Melo ${ }^{1}$ Jacqueline Maria Resende Silveira Leite ${ }^{2}$
}

\section{RESUMO}

Objetivo. Avaliar e identificar o desenvolvimento motor de crianças institucionalizadas, que estejam dentro da Primeira infância, através da Escala de Alberta (Alberta Infant Motor Scale). Método. Foi realizado um estudo observacional com 13 crianças que tinham de 0 a 18 meses de idade. As crianças foram avaliadas nas posiçóes prono, supino, sentado e ortostática. A cada item observado de atividade motora foi creditado 1 ponto, somente a criança que não realizou nenhuma atividade motora nas posiçóes citadas foram creditado zero pontos. Assim a soma dos pontos creditados foi à pontuação do posicionamento na AIMS. Quanto mais alta a classificação percentual menor a chance de um bebê demonstrar atraso no seu desenvolvimento motor. Resultados. Não se encontrou no presente estudo uma diferença quando comparamos a instituiçáo com o que consta na literatura, sendo, estatisticamente não significante. Conclusáo. Todas as crianças encontram-se dentro dos padróes normais de desenvolvimento motor da escala AIMS.

Unitermos. Desenvolvimento motor, primeira infância, AIMS.

Citaçáo. Melo FR, Leite JMRS. Avaliação do Desenvolvimento Motor de Crianças Institucionalizadas na Primeira Infância.

\begin{abstract}
Objective. This study aimed to identify and assess the motor development of institutionalized children who are in their early childhood according to the Alberta Infant Motor Scale (AIMS). Method. It was conducted an observational study with 13 children from 0 to 18 months old. The children were assessed in the prone, supine, seated and orthostatic positions. Their records were plotted on the Alberta Scale (AIMS) graph, thus providing the punctuation of each participant. For each motor activity observed, 1 point was credited. Children who did not effect any motor activity received 0 (zero) points. This way, the sum of the points credited to the children punctuated their positioning in the AIMS. The likelihood of a baby disclosing delayed motor development was lower the higher the classification in percentage. Results. It was not possible to verify a significative difference ( $\mathrm{p}$ $\geq 0,05)$ when the researched institution was compared to the literature reviewed in this study. In fact, the result found was statistically. Conclusion. All children who participated in this experiment were considered within the normal patterns of the AIMS.
\end{abstract}

Keywords. Motor development, early childhood, AIMS.

Citation. Melo FR, Leite JMRS. Assessment of Motor Development in Institutionaliuzed Children in their Early Childhood.
Trabalho realizado na Instituiçáo pública - Centro Espírita Dr. Augusto Silva na creche Emília de Andrade da cidade de Lavras, Lavras-MG, Brasil. 1. Acadêmica do curso de Fisioterapia do Centro Universitário de Lavras UNILAVRAS, Lavras-MG, Brasil.

2. Mestre em Medicina Interna e Terapêutica, Professora do Centro Universitário de Lavras - UNILAVRAS, Lavras-MG, Brasil.
Endereço para correspondência:

Flaviane Rezende Melo Rua Comendador José Esteves, 646, Apto 402, Centro CEP 37200-000, Lavras-MG, Brasil.

Tel.: 35 8857-1141

E-mail: flavismel@hotmail.com

Relato de Caso Recebido em: 07/05/10 Aceito em: 04/03/11 Conflito de interesses: não 


\section{INTRODUÇÃO}

O termo desenvolvimento refere-se à série de modificaçóes que o organismo apresenta até atingir a maturidade. É geralmente usado para incluir todas as modificaçôes pré-natais e pós-natais com exceção do crescimento, que corresponde ao aumento de tamanho ${ }^{1}$.

Quando uma criança nasce e perde a segurança da mãe, o ambiente homeostático no útero nas adjacências não familiares, ele ou ela é completamente dependente dos outros para todas as necessidades. Instantaneamente, as habilidades motoras da criança mudam; os movimentos livres experimentados no útero são restritos pela gravidade. Ao invés de chutar, dar cambalhotas e rolar, o neonatal não pode nem controlar a posição de sua cabeça. Pelos próximos doze meses, uma metamorfose motora ocorre, e a criança dirige todas as habilidades motoras necessárias pela independência neste novo ambiente ${ }^{2}$.

$\mathrm{O}$ ambiente em que o lactente vive pode dar diferentes formatos ou moldar aspectos do seu comportamento motor. $\mathrm{O}$ ambiente positivo age como facilitador do desenvolvimento normal, pois possibilita a exploração e interação com o meio. Entretanto, o ambiente desfavorável letífica o ritmo de desenvolvimento e restringe as possibilidades de aprendizado da criança. Paralelamente aos fatores de risco biológico, as desvantagens ambientais podem influenciar negativamente a evolução do desenvolvimento das crianças ${ }^{3}$.

Este trabalho tem por objetivo identificar possíveis desvios do desenvolvimento motor de crianças institucionalizadas, que estejam dentro da Primeira infância, através da Escala de Alberta (AIMS - Alberta Infant Motor Scale), avaliando na prática o que consta na literatura.

\section{MÉTODO}

\section{Amostra}

Foram avaliadas 13 crianças tanto do sexo masculino quanto feminino, sendo estas com idade entre seis meses e dois dias a dezessete meses e vinte cinco dias da instituição pública - Centro Espírita Dr. Augusto Silva na creche Emília de Andrade da cidade de Lavras - MG. As crianças que estavam resfriadas, internadas ou por qualquer outro motivo de doença, não se encontravam na creche, não foram avaliadas.

A idade utilizada pela Escala AIMS é de 0 a 18 meses, idade em que se encontrava as crianças da creche, a escala consiste de 58 itens organizados dentro de 4 posturas: prono (12), supino (9), sentado (12) e de pé (16)².

Antes de participarem da pesquisa os responsáveis pelos menores e a instituição receberam todas as informaçóes relacionadas ao estudo e assinaram um Termo de Autorização, permitindo e estando de acordo com a execução da mesma. O projeto de pesquisa foi submetido e aprovado pelo Comitê de Ética e Pesquisa (CEP) do Centro Universitário de Lavras, UNILAVRAS. Número do protocolo: 0013.0.189.000-09.

\section{Procedimento}

Individualmente, as crianças foram trazidas pelas cuidadoras e colocadas no colchonete. As crianças foram avaliadas nas posiçóes prono, supino, sentado e ortostática, cujos registros foram efetuados e transportados para o gráfico fornecido pela mesma escala, obtendo-se assim a pontuação de cada participante.

Uma vez que o bebê começava a se movimentar, uma série de itens era observado num curto período de tempo. As autoras deste projeto observavam e analisavam cada movimento do bebê e quando necessário apenas mudava de posições (prono, supino, sentado e ortostática).

O tempo foi de 20 a 30 minutos para completar toda a avaliação. Uma grande porção deste tempo foi usada para aclimatação do bebê para o teste de situação. As crianças que estavam doentes não foram avaliadas.

A cada item observado de atividade motora foi creditado 1 ponto, somente a criança que não realizou nenhuma atividade motora nas posiçóes citadas foram creditado zero pontos. Assim a soma dos pontos creditados foi à pontuação do posicionamento na AIMS.

Quanto mais alta a classificação percentual menor a chance de um bebê demonstrar atraso no seu desenvolvimento motor.

\section{Análise estatística}

Os resultados dos dados analisados foram obtidos através de cálculos estatísticos de média e desvio padrão do Escore AIMS, sendo os pontos obtidos inseridos na curvapadrão da Metodologia AIMS. Os dados foram analisados com o auxílio do teste $\mathrm{t}$ - student $(\mathrm{p} \geq 0,05)$ dentro dos limites de normalidade previstos pela escala AIMS. 


\section{RESULTADOS}

Não se encontrou no presente estudo uma diferença quando comparamos o desempenho de crianças na instituição com o que consta na literatura, conforme Gráfico 1 e Tabela 1.

\section{DISCUSSÃO}

$\mathrm{Na}$ creche os participantes permaneciam em berçários e em espaços razoavelmente grandes, cercados, por um grande período, brincando, explorando o ambiente e recebendo estímulos, não verificando atraso motor.

Em estudo realizado, os participantes estavam distribuídos em berçários, conforme a idade, e o espaço físico onde foi realizada a pesquisa proporcionavam poucas oportunidades para o exercício da motricidade livre, considerando o grande número de crianças em cada berçário ${ }^{3}$.

Um grande número de crianças, nos estudos analisados ocupava espaços reduzidos, e o atraso motor verificado em seus estudos pode ter relação direta com o ambiente e a falta de estimulação ${ }^{3}$.

Relata que quando uma criança é mantida durante muito tempo sem condiçôes para se deslocar livremente, ela pode sofrer prejuízo em seu aprendizado e na aquisição de suas habilidades motoras ${ }^{4}$.

O arranjo espacial aberto de uma creche as educadoras tem uma maior disponibilidade para atender as crianças que as procuram, observar suas açôes e estabelecer contato mais individualizado com aquelas que ne-

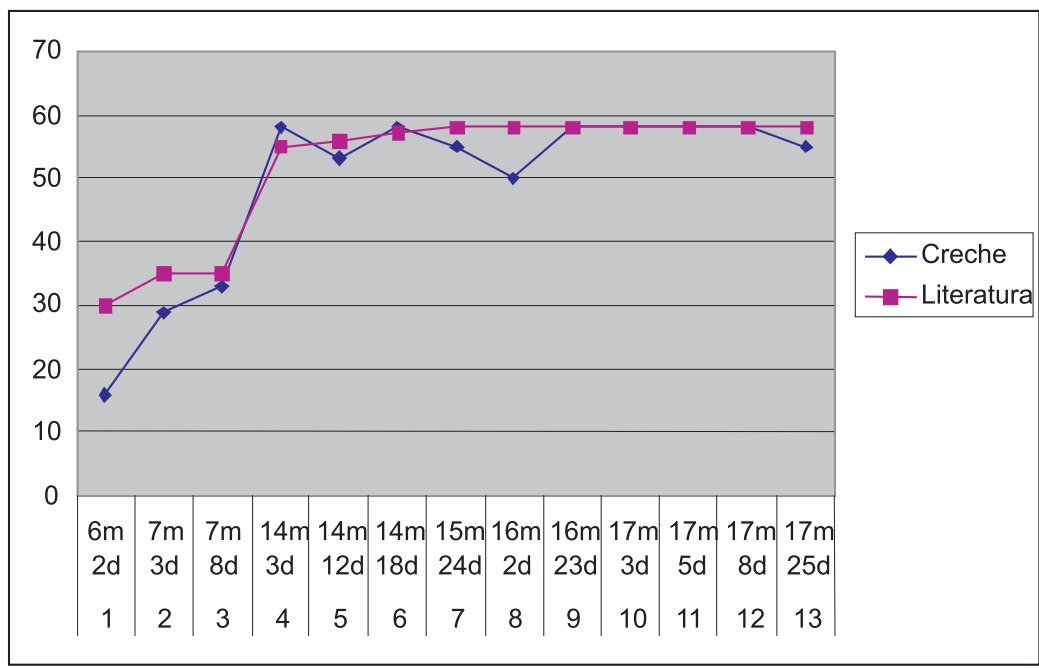

Gráfico 1. Valores percentuais de acordo com a AIMS.

A idade das crianças encontra-se em meses e dias. cessitarem maior atenção, ou desenvolver atividades com um pequeno grupo de crianças 5 .

$\mathrm{Na}$ creche o ambiente era lúdico (paredes coloridas, ambiente alegre, acolhedor e estimulante) onde as crianças passavam a maior parte do tempo. No ambiente onde elas dormiam, pouca iluminação o que tornava o ambiente mais agradável e propício.

As pessoas que trabalham diretamente com esta população devem estar atentas às questôes do desenvolvimento motor, de tal forma que possam prevenir ou minimizar alguns problemas 5 .

Havia duas cuidadoras para cada berçário, sendo que uma delas tinha conhecimento sobre desenvolvimento motor normal e a outra contava apenas com suas experiências.

Em alguns casos, o atraso no Desenvolvimento Motor Normal pode surgir não só como falta de estimulaçáo dada pelas cuidadoras no período em que passam nas instituições mas também por não receberem estímulos em suas casas, podendo ser devido à falta de conhecimento dos familiares, assim como, a falta de tempo por trabalharem fora, com isso algumas diferenças no DMN de lactentes podem surgir na presença de variaçôes nas práticas maternas, não havendo atraso devido à falta de estimulação das cuidadoras, podendo ser a dos familiares.

As crianças do presente estudo permaneciam de 8 a 9 horas nas instituiçóes e o restante em suas casas. Não foi avaliado neste estudo como as crianças são estimuladas em suas casas por seus familiares, principalmente por suas mães.

As práticas maternas influenciam o desempenho motor a partir do $9^{\circ}$ mês de vida, e as experiências e o tempo gasto em uma posição podem influenciar a sequência e a época de aquisição de certas habilidades motoras $^{6}$.

Neste estudo foi utilizado como ferramenta de avaliação a Alberta Infant Motor scale (AIMS), que é um instrumento avaliativo observacional que proporciona uma identificação de atraso e monitorização do desenvolvimento motor nos primeiros dezoito meses de vida. A identificação 
Tabela 1

Valores percentuais de acordo com a AIMS

\begin{tabular}{cccc}
\hline Idade & Creche & Literatura & Valores de p \\
\hline & $\begin{array}{c}\text { Prono/Supino/Sentar/ } \\
\text { Ficar em pé } \\
21 / 9 / 12 / 16\end{array}$ & $\begin{array}{c}\text { Prono/Supino/Sentar/ } \\
\text { Ficar em pé } \\
21 / 9 / 12 / 16=58\end{array}$ & $60 \%$ \\
\hline 6 meses 2 dias & 18 & 30 & $82,86 \%$ \\
7 meses 3 dias & 29 & 35 & $94,44 \%$ \\
7 meses 8 dias & 34 & 36 & $103,7 \%$ \\
14 meses 3 dias & 56 & 54 & $94,55 \%$ \\
14 meses 12 dias & 52 & 55 & $100 \%$ \\
14 meses 18 dias & 56 & 56 & $98,25 \%$ \\
15 meses 24 dias & 56 & 57 & $87,71 \%$ \\
16 meses 2 dias & 50 & 57 & $100 \%$ \\
16 meses 23 dias & 57 & 57 & $100 \%$ \\
17 meses 3 dias & 58 & 58 & $100 \%$ \\
17 meses 5 dias & 58 & 58 & $100 \%$ \\
17 meses 8 dias & 58 & 58 & $96,55 \%$ \\
\hline meses 25 dias & 56 & 58 & \\
\hline
\end{tabular}

dos dados permite ao examinador determinar o percentual em que se encontra a criança avaliada.

$\mathrm{O}$ atraso no desenvolvimento aparece como única queixa que motivou a procura de atendimento em $41 \%$ dos casos, e, nos demais, são relatadas outras dificuldades da criança. A maioria das crianças do grupo de queixa única tem idades inferiores a três anos (89\%) e as do grupo de queixa múltipla tem idades entre seis e oito anos (77\%). Quando a criança é pequena, a preocupação dos pais parece mais centrada no atraso geral do desenvolvimento do filho, sinalizado pela dificuldade em cumprir determinadas tarefas características de sua faixa etária. A procura de atendimento pelos pais, para a maioria dessas crianças, envolve a busca de orientação, visando à estimulação precoce do seu desenvolvimento ${ }^{7}$.

Apenas um único caso apresentou-se acima do percentil 50 (3\%), com os demais 29 participantes (97\%) apresentando resultado abaixo deste percentil 5 .

A avaliação dos lactentes pela AIMS constitui um bom instrumento para analisar a seqüência de aquisiçôes motoras ${ }^{8}$.

A escala de AIMS propóe uma medida observacional do desenvolvimento motor de crianças, avaliando o desenvolvimento sequencial de marcos motores desde o nascimento até a marcha independente, sendo de fácil aplicação e interpretação.
Como consideraçóes finais, sugerimos que para próximos estudos seja avaliado um número maior de crianças e creches, devido ao aumento do número de crianças com atraso motor na primeira infância, mesmo estando institucionalizadas, não recebem os estímulos necessários e adequados pelo fato de ter poucas cuidadoras e muitas crianças.

\section{CONCLUSÃO}

Não se encontrou no presente estudo uma diferença significativa ( $p \geq 0,05)$ quando comparamos a instituição com o que consta na literatura, sendo, estatisticamente não significante. Assim, todas as crianças encontram-se dentro dos padrôes normais de desenvolvimento motor da escala AIMS.

\section{REFERÊNCIAS}

1.Gardner GRAI, O’ Rahilly. Anatomia. 4a edição. Rio de Janeiro: Guanabara Koogan, 1988, 830p.

2.Piper, Martha C. Darrh Johanna. Motor Assessment of The Developing Infant. W.B. Saunders Company. 1994, 210p.

3.Castanho AAG, Assis SMB. Caracterização do Desenvolvimento Motor da Criança Institucionalizada. Revista Fisioterapia Brasil 2004;8:5-6.

4.Barros KMFT, Fragoso AGC, Oliveira ALB, Filho JEC, Castro RM. Do Environmental Influences Alter Motor Abilities Acquisition? A Comparison 
among childrem from day-care centers and private schools. Arq Neuropsiquiatria 2003; 61(2-A):170-5.

http://dx.doi.org/10.1590/S0004-282X2003000200002

5.Meneghini R, Carvalho MC. Arranjo espacial na creche: espaços para interagir, brincar isoladamente, dirigir-se socialmente e observar o outro. Psicologia: Reflexão e Crítica 2003, p.367-78.

http://dx.doi.org/10.1590/S0102-79722003000200017

6.Silva PL, Santos DCC. Gonçalves VMG. Influência de Praticas Maternas no Desenvolvimento Motor de Lactentes do $6^{\circ}$ ao $12^{\circ}$ Meses de Vida. Revista Brasileira de Fisioterapia 2006;10:225-31.

http://dx.doi.org/10.1590/S1413-35552006000200014

7.Gramilha SSV, Martins MAO. Condiçôes Adversas na Vida de Crianças com Atraso no Desenvolvimento. Medicina, Ribeirão Preto 1997, p.259-67.

8.Formiga CKMR, Pedrazzani ES, Tudella E. Desenvolvimento motor de lactentes pré-termo participantes de um programa de interaçáo fisiterapêutica precoce. Revista Brasileira de Fisioterapia 2004;8:239-245. 